\title{
Mapping Urban Environmental Performance with Emerging Data Sources: A Case of Urban Greenery and Traffic Noise in Sydney, Australia
}

\author{
Zahra Nourmohammadi ${ }^{1}$, Tanapon Lilasathapornkit ${ }^{2}{ }^{\oplus}$, Mudabber Ashfaq ${ }^{2}$, Ziyuan Gu ${ }^{2}$ and \\ Meead Saberi ${ }^{2, *}$ (I) \\ 1 Department of Industrial Engineering, Sharif University of Technology, Tehran 14588-9694, Iran; \\ nourmohammadi.za@gmail.com \\ 2 Research Center for Integrated Transport Innovation (rCITI), School of Civil and Environmental Engineering, \\ University of New South Wales (UNSW), Sydney, NSW 2052, Australia; \\ t.lilasathapornkit@unsw.edu.au (T.L.); m.ashfaq@unsw.edu.au (M.A.); ziyuan.gu@unsw.edu.au (Z.G.) \\ * Correspondence: meead.saberi@unsw.edu.au
}

check for updates

Citation: Nourmohammadi, Z.; Lilasathapornkit, T.; Ashfaq, M.; Gu, Z.; Saberi, M. Mapping Urban Environmental Performance with Emerging Data Sources: A Case of Urban Greenery and Traffic Noise in Sydney, Australia. Sustainability 2021, 13, 605. https://doi.org/10.3390/ su13020605

Received: 8 December 2020 Accepted: 6 January 2021 Published: 10 January 2021

Publisher's Note: MDPI stays neutral with regard to jurisdictional clai$\mathrm{ms}$ in published maps and institutional affiliations.

Copyright: () 2021 by the authors. Licensee MDPI, Basel, Switzerland. This article is an open access article distributed under the terms and conditions of the Creative Commons Attribution (CC BY) license (https:// creativecommons.org/licenses/by/ $4.0 /)$.

\begin{abstract}
Measuring urban environmental performance supports understanding and improving the livability and sustainability of a city. Creating a more livable and attractive environment facilitates a greater shift to active and greener transport modes. Two key aspects, among many others, that determine the environmental performance of an urban area are greenery and noise. This study aims to map street-level greenery and traffic noise using emerging data sources including crowd-sourced mobile phone-based data and street-level imagery data in Sydney, Australia. Results demonstrate the applicability of emerging data sources and the presented advanced techniques in capturing the seasonal variations in urban greenery and time-dependent nature of traffic noise. Results also confirm the presence of a negative correlation between urban greenery and traffic noise.
\end{abstract}

Keywords: urban; environmental performance; greenery; canopy; traffic noise; Sydney

\section{Introduction}

With rapid urbanization and motorization of travel in cities over the past few decades, various environmental issues have emerged that largely affect urban livability and environmental sustainability, especially in the city centers where human activities and mobility usually concentrate. Evidence has shown that traffic noise and urban heat islands are two of the key factors contributing to the decline in life quality and the overall well-being of residents and that such negative effects are the strongest in dense and congested city centers [1-9].

The World Health Organization (WHO) has published a series of reports discussing how and to what extent environmental noise affects society, both physically and mentally $[10,11]$. With private cars being the dominant mode used to travel in many cities, increased urban space is dedicated to cars rather than to people. Many communities tend to emphasize vehicle mobility based on which urban infrastructure is planned, at the cost of reduced walkability. We have witnessed the replacement of urban green space as a result of this car-centric development, whereas the city should be planned for the people, not cars. It is also known that urban greenery has a close relationship with public health and the environment [12].

Urban greenery and traffic noise are two key factors contributing to a city's environmental performance, livability, and walkability. The challenging question concerns, however, how we can better measure, map, and thus understand urban environmental performance from a spatial and temporal perspective using emerging data sources such crowd-sourced, distributed, imagery, and mobile phone-based data. Spatial quantification and visualization of urban greenery and traffic noise are ubiquitous in delivering 
people-centric planning strategies. If a city decides to improve its walking environment by providing more green canopies in the cityscape and reducing traffic noise through travel demand management, a greater shift to active and green transport is foreseeable.

Noise mapping was initially developed in Europe and has been extensively applied and developed since the issuance of the Environmental Noise Directive [13]. More recently, there has been a growing number of initiatives that use a mobile phone-based participatory approach to measure and map noise in urban areas. This makes it possible to collect both physical sound-level data and perceptual data on the sound environment [14]. A case study of Toronto by Zou et al. [15] demonstrated that noise variability was predominantly spatial in nature, rather than temporal, and there was a high correlation between seasonal noise patterns. Noise maps can be used to identify noise levels within cities, identify areas with greater exposure, assess future scenarios, help to identify the presence of this invisible contaminant, and serve as a basis to adopt actions to reduce noise levels through structural and nonstructural measures such as sustainable urban planning [16]. As an example, Cai et al. [17] used empirical noise and traffic data to optimize a regional traffic noise estimation model and developed traffic noise maps of Guangzhou, China. Bilasco et al. [18] proposed an information system model which generated a noise map using sound measurements, building heights, land uses, a digital land altitude model, and wind speed and direction in GIS software.

Aerial images, remote sensing, and GIS-powered tools have been widely used to monitor and manage urban greenery [19]. Unbalanced allocation of urban greenery and the risk of health challenges are shown to be correlated [20,21]. Street-level imagery data such as Google Street View (GSV) provide a high spatial resolution that enables providing new insights to urban greenery analysis [22,23]. A study by Yang et al. [24] indicated that measuring street greenery through GSV can be an advanced method for assessing residents' daily exposure to urban greenery. They found that urban greenery observed in GSV images was positively associated with the walking behavior of older adults. Li et al. [25] investigated different types of urban greenery using multisource spatial datasets. They observed different spatial distributions and associations with the social status of residents related to different types of urban greenery. The literature suggests that a large number of ecosystem services benefitting the urban population are provided by trees, for instance, reducing the temperature through shading and evapotranspiration [26].

The objective of this paper is thus twofold. We first aim to quantify and visualize the spatial distribution of urban greenery at the street level in Sydney, as a case study, by exploring Google Street View (GSV) images across different seasons. We then aim to estimate traffic noise and map its spatial and temporal distribution in Sydney by exploring both crowd-sourced mobile phone-based data and traffic volume data at different times of day.

\section{Methods and Data}

\subsection{Mapping Urban Greenery}

The growing global awareness of climate change and rapid urbanization has put urban heat and greenery at the center of many discussions on the future of sustainable planning. Urban greenery improves amenities as tree canopies provide shade for pedestrians and cyclists and reduce traffic noise. To quantify and visualize the street-level greenery in Sydney, as a case study, we use Treepedia [27], an open-source tool developed by the MIT Senseable City Lab using GSV images. The green canopy is measured by the Green View Index (GVI) on a scale of $0-100$, representing the percentage of the canopy coverage of any location from different vertical view angles ( -45 degrees, 0 degrees, and 45 degrees) and during different seasons (winter and summer). See Appendix A.

The overall framework for quantifying urban greenery consists of three steps. The very first step is to sample multiple locations in the network based on which the GVI values are to be calculated. With these sampled locations, the second step is to retrieve the GSV images using the Google Street View API. Finally, the GVI of each location can be 
calculated considering multiple horizontal and vertical angles to account for both tall trees and ground vegetation. In what follows, we will introduce each of these steps, respectively.

\subsubsection{Location Sampling}

First, a continuous road network must be represented in a discrete manner by sampling multiple locations. These locations are used to calculate the GVI. In Figure 1, we illustrate how location sampling was performed for the Sydney central business district (CBD). The street network as the original input was transformed into a discrete format containing multiple locations at every $40 \mathrm{~m}$. The distance between the sampled locations can be adjusted depending on the size of the area as well as user preferences. We sampled these locations evenly across the network which were then fed into the Google Street View API so that corresponding GSV images could be retrieved. Due to the high computational cost as well as the monetary cost of using the Google Street View API, we selected the sampling distance of $40 \mathrm{~m}$ that is believed to cover a suitable field of view in the street view images without distorting the quality of the greenery index. A sensitivity analysis may be needed to find the optimal sampling distance.

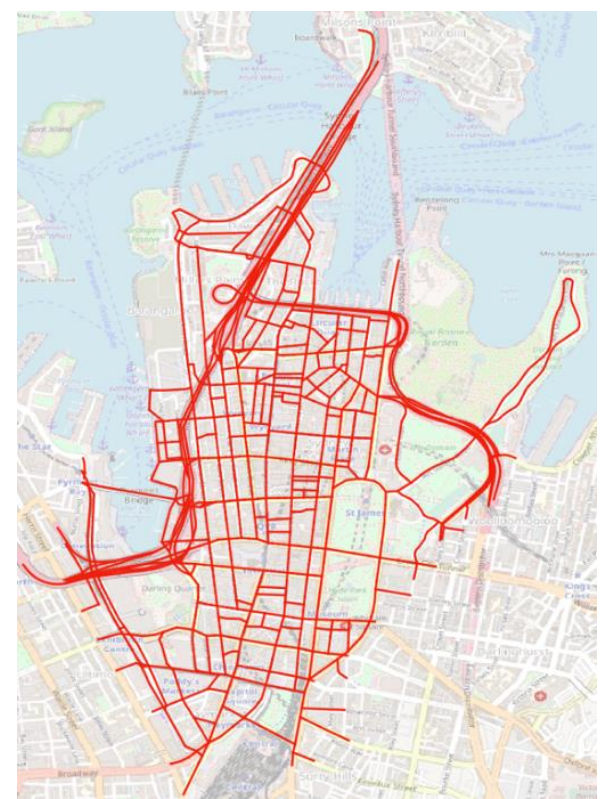

(a)

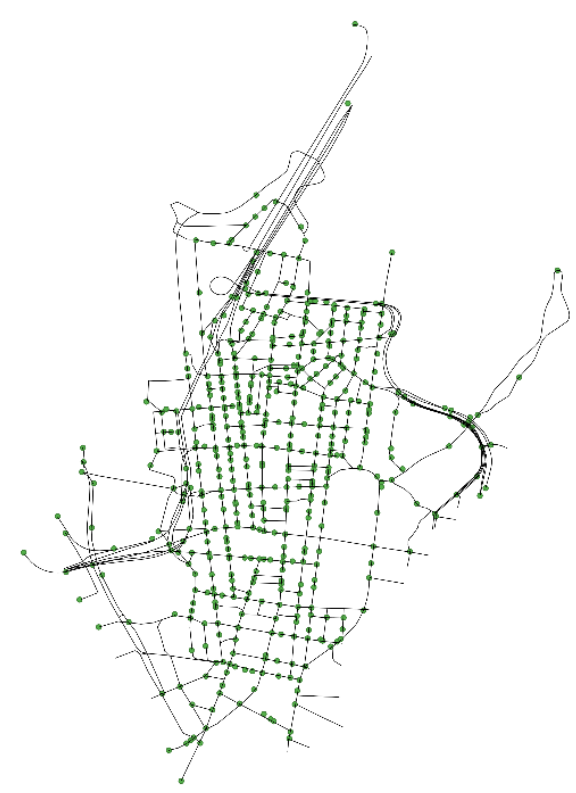

(b)

Figure 1. (a) Street network of the Sydney central business district (CBD); and (b) sampled locations at every $40 \mathrm{~m}$.

\subsubsection{Retrieving Metadata}

With all the locations sampled, the next step was to retrieve the metadata corresponding to each of the sampled locations. Metadata include necessary location information such as the GSV image date, latitude, longitude, and tilt specifications. This information was used for retrieving the GSV images at all the sampled locations through the Google Street View API. One significant limitation of the GSV images is the unavailability of images across different seasons for all locations. Some locations may only have images from wintertime or summertime only. This creates an inconsistency in the analysis which may require further data sources to improve the greenery estimation.

\subsubsection{Calculating GVI using GSV Images}

The GVI was calculated considering the obstruction of tree canopies in the GSV images and classifying the pixels therein. On a scale of 0-100, it quantifies the canopy coverage at any location (i.e., the GVI) as the ratio of the total green area from all the images to the total 
area covered by these images (Li et al., 2015). The panorama covers multiple horizontal and vertical angles (see Figure 2).
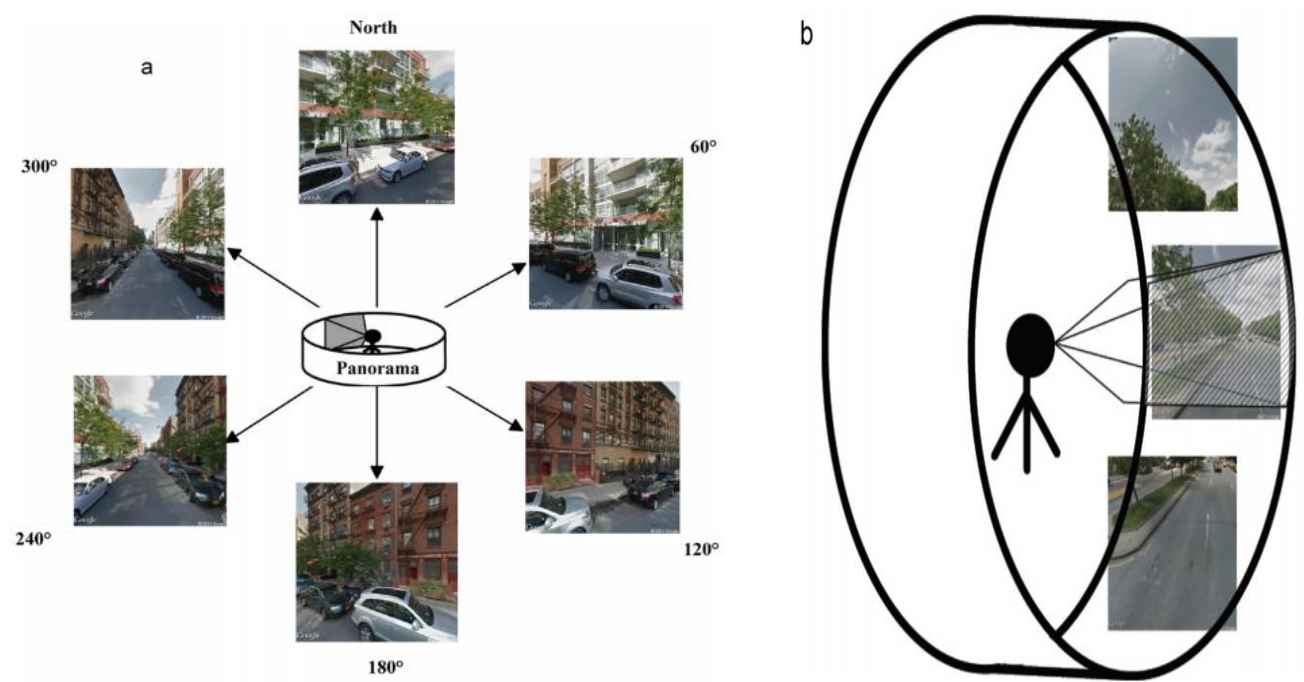

Figure 2. Google Street View (GSV) images covered from multiple (a) horizontal and (b) vertical angles [28].

To capture greenery from images, the green pixels must be identified, which can be accomplished by color differentiating between red, blue, and green. Although some artificial green features could be misclassified as greenery, this misclassification has limited effect on the subsequent analysis in real applications given the fact that artificial green features only account for a small portion of the cityscape. Note that the initial classification contains some spark points considered as noises. In the refined classification, these are filtered out. For each sampled location in the network, we calculated the GVI. We took the retrieved metadata as input and collected the corresponding GSV images using the Google API. If these images were chosen at every 60 degrees horizontally (see Figure 2a), we ended up with a total of six images for each vertical angle. That is, for each vertical angle, we calculated the GVI using all the six horizontal images. We differentiated between different vertical angles because it allows us to study different types of greenery in the city space, e.g., tall trees vs. low bushes. Further, when collecting GSV images, we have the option to distinguish between different seasons from which these images are taken. This feature allows us to study the seasonal effect on urban greenery.

\subsubsection{Visualization Techniques}

The result presented in Figure 3a cannot be used directly for visualization purposes because the network is currently represented in a discrete format by a finite number of sampled locations. To obtain a continuous representation of urban greenery along the streets, we performed an interpolation from the GVI values of the existing sampled locations. The interpolation results are shown in Figure $3 \mathrm{~b}$. We can see that the GVI values are now continuous across the entire network, forming a so-called raster image. The remaining task to be conducted was to mask the raster considering only roadsides where urban greenery was expected. To do so, we considered a polygon of the road network and a buffer area surrounding the streets with a width of $10 \mathrm{~m}$ (see Figure 3c). The final result after masking is illustrated in Figure 3d. It shows how urban greenery is spatially distributed along the streets in the network. 


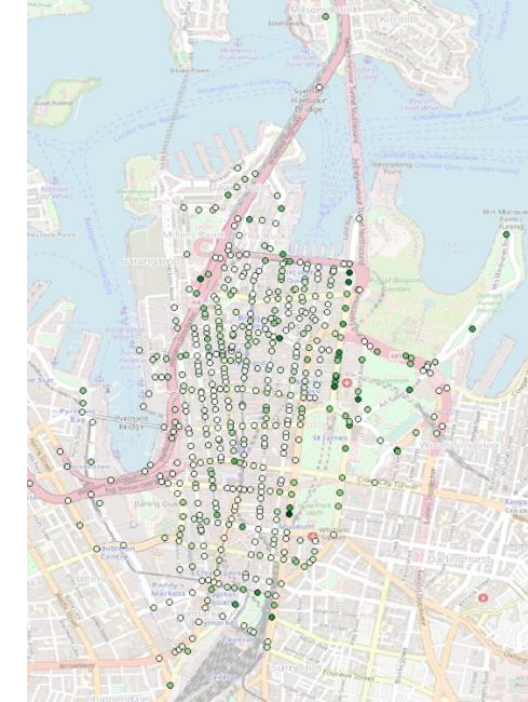

(a)

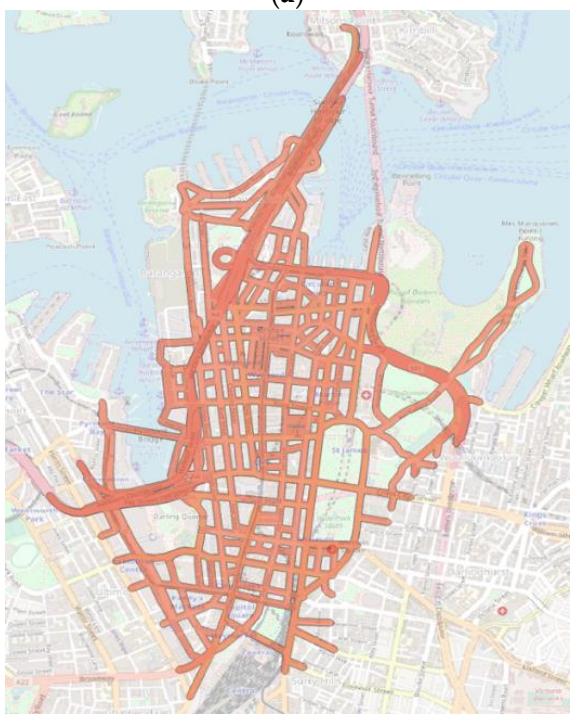

(c)

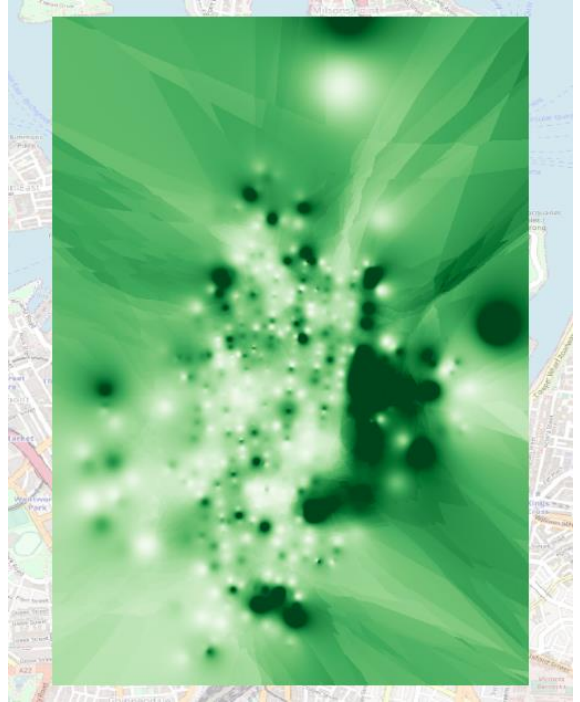

(b)

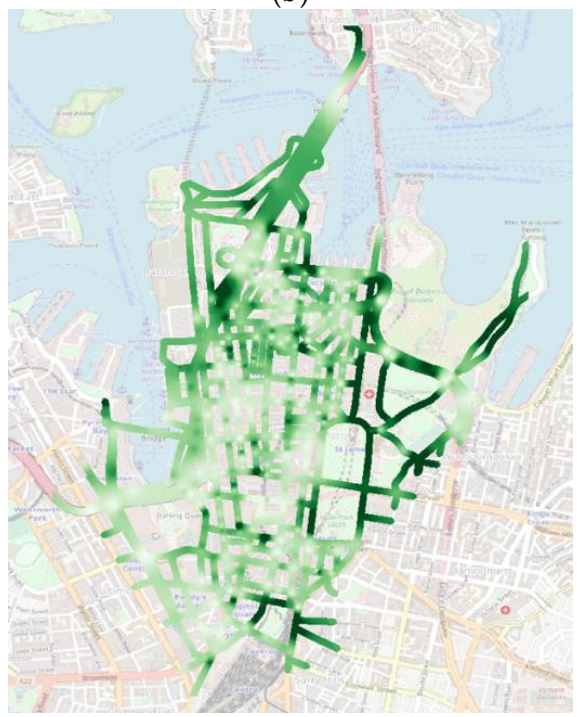

(d)

Figure 3. A comparison between (a) the original discrete representation of urban greenery and (b) the rasterized continuous representation after interpolation. (c) Road network of the Sydney CBD with a buffer area of $10 \mathrm{~m}$ width; and (d) masked representation of urban greenery based on the raster.

\subsection{Mapping Traffic Noise}

Noise, defined as "unwanted sound", is perceived as an environmental stressor and nuisance that affects social behavior and is shown to be associated with hypertension, cardiovascular diseases, and psychological symptoms. To estimate traffic noise levels in Sydney, we used NoiseModelling, a plugin of the open source OrbisGIS that enables the production of urban noise maps based on the French standard method for road noise emission and the NMPB method for noise propagation [29]. It consists of two steps: estimation of traffic noise emission over the road network and calculation of sound levels propagating over a receiver's grid. For mathematical details, we refer to the above reference. We chose NoiseModelling as our evaluation tool over some other alternatives such as CNOSSOS-EU [30-32] because the former offers estimation of both noise emission and propagation across the network and is readily implementable as an open-source package using GIS.

The key input data to the traffic noise model were the average traffic volumes and speeds across the area of interest. We obtained traffic volumes across the Sydney CBD at three time intervals including the morning peak 7-9 a.m., the afternoon peak 4-6 p.m., and 
the off-peak periods 9 a.m. -4 p.m. and 6 p.m. -7 a.m. The traffic volume estimates were built from a range of data inputs including a detailed computational representation of the road network, household travel surveys, census data, public transport route information, parking price data, toll road usage data, educational enrolment data, airport passenger data, car ownership data, tourism data, current traffic count data (with/without vehicle classification), and public transport patronage data (boardings/alightings) [33].

To calibrate the noise model, observational noise data were collected using NoiseCapture, a free crowd-sourced mobile phone-based application. It collects environment noise levels and uses mobile phone GPS to locate receiver positions. See Figure 4 for an illustration of the spatial extent of the empirical noise data collection. Data were collected at different times of the day across a few weekdays for multiple 1-h and 2-h periods. A digital noise level meter $(30-130 \mathrm{~dB}+/-1.5 \mathrm{~dB})$ with a frequency range from 31.5 to $4 \mathrm{~K} \mathrm{hz}$ was also used to adjust the mobile phone-based noise measurements.

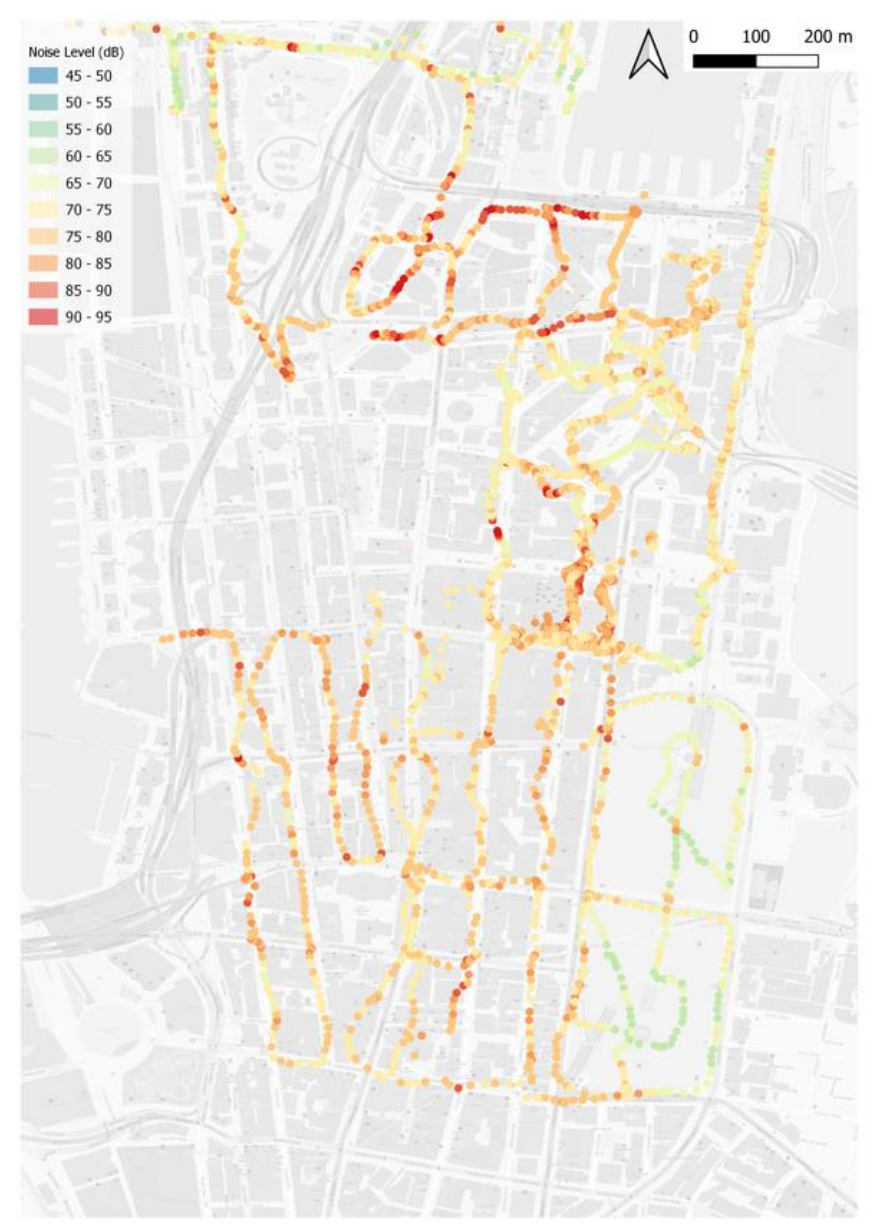

Figure 4. Spatial distribution of collected empirical noise data across the Sydney CBD using the NoiseCapture mobile application. Colors, as shown in the legend, represent measured noise level in $\mathrm{db}$.

\subsubsection{Data Processing: Traffic Volumes and Building Footprints}

Vehicles in the traffic data were categorized as light vehicles vs. commercial vehicles (i.e., heavy vehicles). Speeds on motorways and other roads in the Sydney CBD were assumed at $80 \mathrm{~km} / \mathrm{hr}$ and $40 \mathrm{~km} / \mathrm{hr}$, respectively. Figure 5 a shows an example of the traffic volume dataset as well as an illustration of how light vehicles are spatially distributed across the Sydney CBD during the morning peak. In addition to the road network, we also needed building footprint polygons in the Sydney CBD which work as barriers to the noise propagation. Building footprints information was obtained from OpenStreetMap (Figure $5 b$ ) that enables exporting such information for any area of interest. 


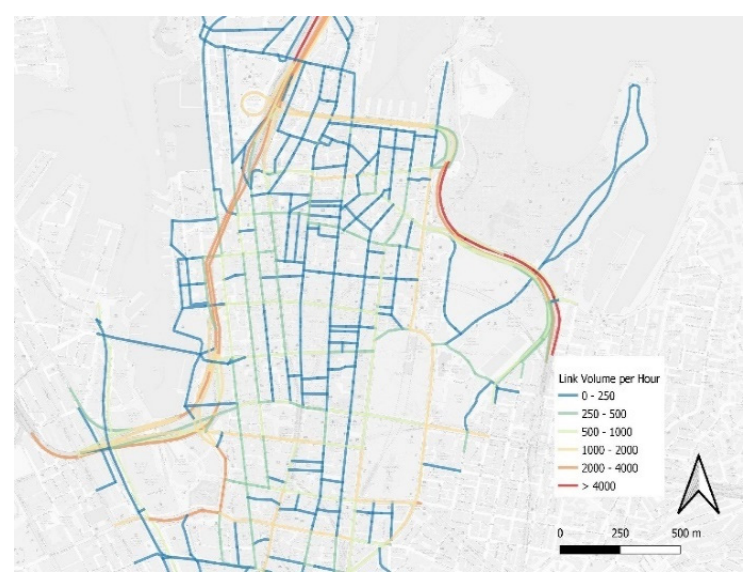

(a)

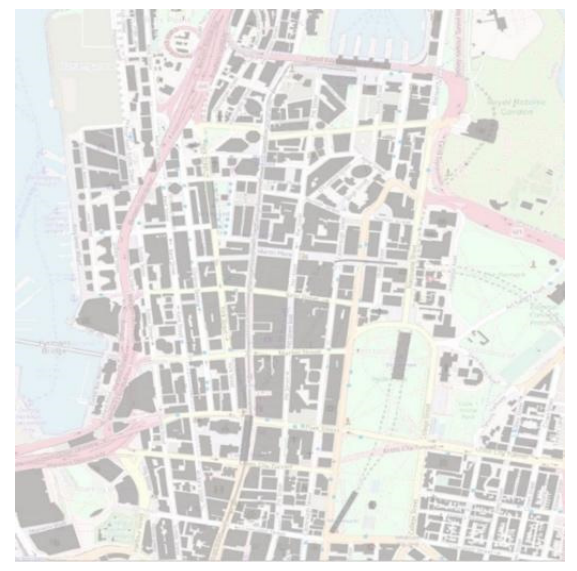

(b)

Figure 5. (a) Spatial distribution of light vehicle volumes across the Sydney CBD during the morning peak. (b) Building polygons, as barriers to the noise propagation, in the Sydney CBD from OpenStreetMap.

\subsubsection{Noise Propagation Model Parameter Calibration}

After launching OrbisGIS and importing traffic volume data and building footprint polygons, we then set up the noise propagation model parameters before simulating how noise propagates in the network. A number of model parameters are adjustable whose formal definitions and value guidelines can be found in [29] including:

- The maximum propagation distance which represents a cut-off distance between each source and receiver.

- The maximum wall seeking distance which permits overlooking walls farther than this distance between each source and receiver.

- The road width which represents an offset distance from the road center line to start creating receivers.

- The receiver's densification value which creates additional receivers at this distance from sources.

- The maximum area of the triangle which sets the maximum surface for the noise map triangular mesh.

- The sound reflection order which represents the maximum number of wall reflections between each source and receiver.

- The sound diffraction order which represents the maximum number of horizontal diffractions between each source and receiver.

- The wall absorption value which indicates the level of noise absorption by the wall.

To calibrate the noise model, we collected comprehensive observational data using the mobile phone application NoiseCapture. A digital noise level meter (see Figure 6a) was also used to see how reliable the data collected by mobile phones were. We expected that the noise levels collected by NoiseCapture would be greater than those measured by the meter because the microphone of a mobile phone can be more sensitive to sounds (not necessarily noise) such as people talking or wind. A comparison between the two collected datasets did confirm our conjecture (see Figure $6 \mathrm{~b}$ ). Thus, we treated the measurements from the sound meter as being more accurate and adjusted the observations from mobile phones accordingly (using their average values). The adjusted noise was considered as the ground truth data and compared with the simulated data in order to calibrate the noise model. 


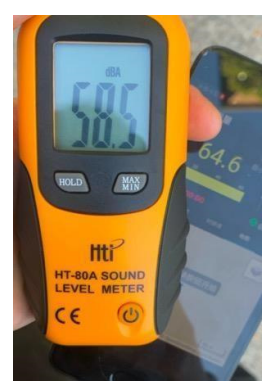

(a)

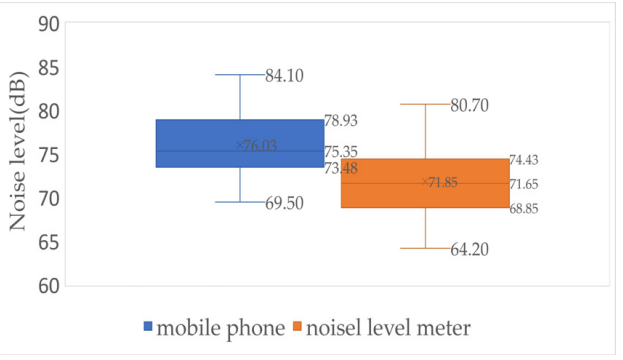

(b)

Figure 6. (a) Digital noise level meter; and (b) comparison between noise levels collected by mobile phones and the meter.

We found that parameters such as the maximum propagation distance (mpd), the reflection order (sro), and the diffraction order (sdo) have significant effects on the simulated noise. The rest have limited impact on the results including the maximum wall seeking distance (mwsd), the road width (rw), the receivers' densification value (rdv), the maximum triangular mesh area (mtma), and the wall absorption value (wav). A total of five parameter sets were tested and compared as summarized in Table 1.

Table 1. Calibration parameter sets of the noise propagation model during the off-peak period.

\begin{tabular}{cccccccccccc}
\hline & \multicolumn{10}{c}{ Model Parameters } \\
\cline { 2 - 11 } & $\mathbf{m p d}(\mathbf{m})$ & $\mathbf{m w s d}(\mathbf{m})$ & $\mathbf{r w}(\mathbf{m})$ & $\mathbf{r d v}(\mathbf{m})$ & $\left.\mathbf{m t m a} \mathbf{( m}^{\mathbf{2}}\right)$ & $\mathbf{s r o}$ & $\mathbf{s d o}$ & wav & Comp. Time (hr) & RMSE & MAE \\
\hline 1 & 750 & 50 & 1.5 & 2.8 & 75 & 0 & 0 & 0.23 & 0.30 & 10.08 & 7.72 \\
2 & 750 & 50 & 1.5 & 2.8 & 75 & 2 & 1 & 0.23 & 6.30 & 9.04 & 6.85 \\
3 & 900 & 50 & 1.5 & 1 & 50 & 0 & 0 & 0.23 & 0.67 & 9.59 & 7.32 \\
4 & 1000 & 50 & 1.5 & 1 & 50 & 0 & 0 & 0.23 & 0.67 & 10.00 & 7.69 \\
5 & 900 & 50 & 1.5 & 1 & 50 & 2 & 1 & 0.23 & 11.30 & 8.94 & 6.79 \\
\hline
\end{tabular}

For the selection of the most appropriate model parameters set, three criteria were used including the computational time, the root mean square error (RMSE), and the mean absolute error (MAE). Results suggested that parameter set 2 provides the most reasonable compromise between the computational time and the model accuracy, which was thus chosen to estimate traffic noise for the Sydney CBD as a case study. A comparison between the observed and the simulated noise for parameter set 2 is provided in Figure 7.

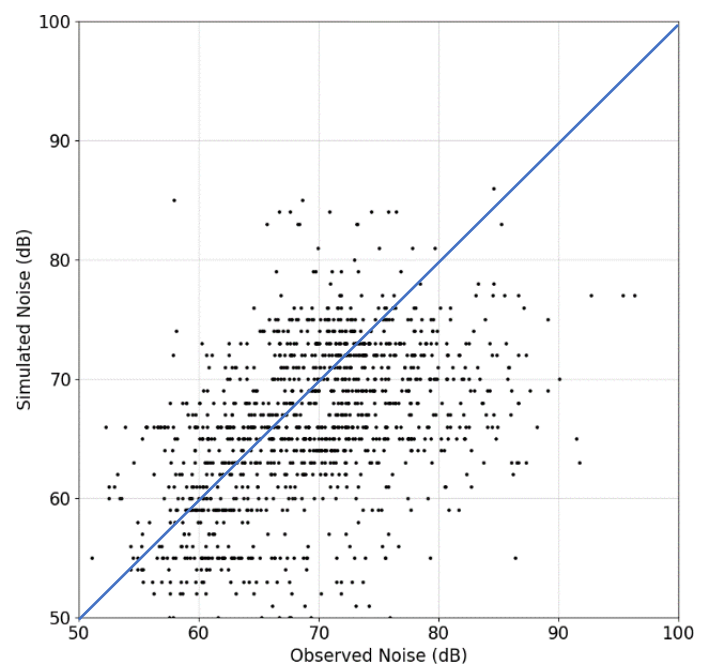

Figure 7. Comparison between the observed and the simulated noise for calibration parameter set 2. Calibration was performed during the off-peak period. 


\section{Results}

\subsection{Urban Greenery}

We first demonstrate and compare the urban greenery mapping results for different vertical angles, examining the applicability of the implemented model and street view imagery to capture both tall trees and low bushes. Without loss of generality, we choose three vertical angles of 0 degrees, +45 degrees, and -45 degrees. Figure $8 \mathrm{a}-\mathrm{c}$ clearly illustrates the effect of the vertical angle on the estimated urban greenery in the study area. With a +45 degrees vertical angle, we seem to capture a larger portion of urban greenery in the cityscape, suggesting the existence of many tall trees along the streets. When the vertical angle reduces to zero degrees, the coverage of green canopies slightly reduces. The lowest level of vegetation is estimated when the vertical angle is -45 degrees, which suggests very limited existence of bushes and ground vegetation in the study area. To reflect the overall greenery at any location, we combine the three vertical angles using a weighted sum assuming a 50\% overlap between the GSV images from the zero degrees vertical angle and those from either +45 degrees or -45 degrees. The final result is illustrated in Figure $8 \mathrm{~d}$. We also consider the seasonal effect (winter vs. summer) on urban greenery. In line with the Australian Bureau of Meteorology [34], the winter is considered to span from April to September, while the summer includes the remaining months in a year. As expected, results demonstrate that urban greenery reduces significantly in winter compared with its peak in summer. See Figure 9 and Appendix B.

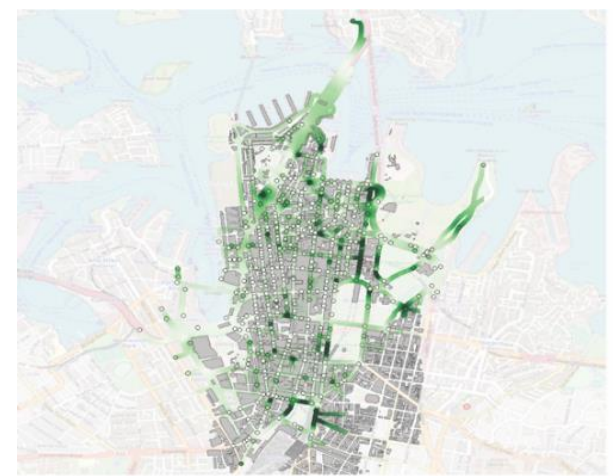

(a)

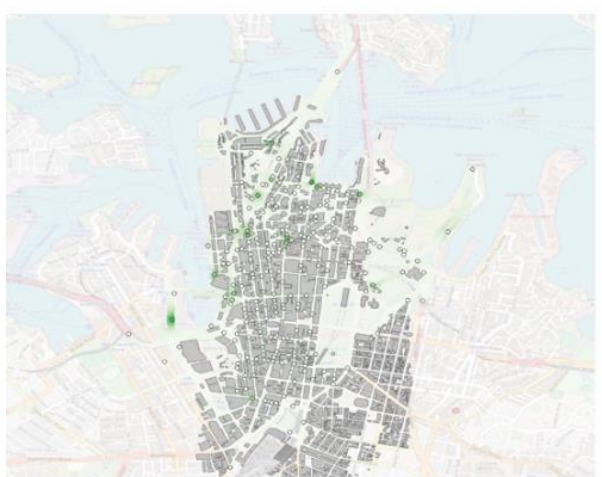

(c)

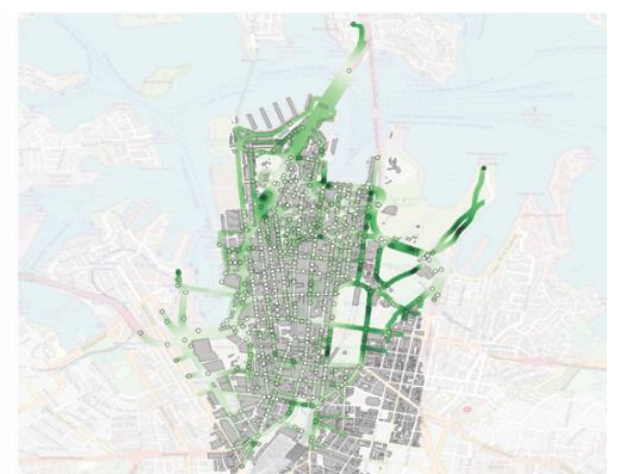

(b)

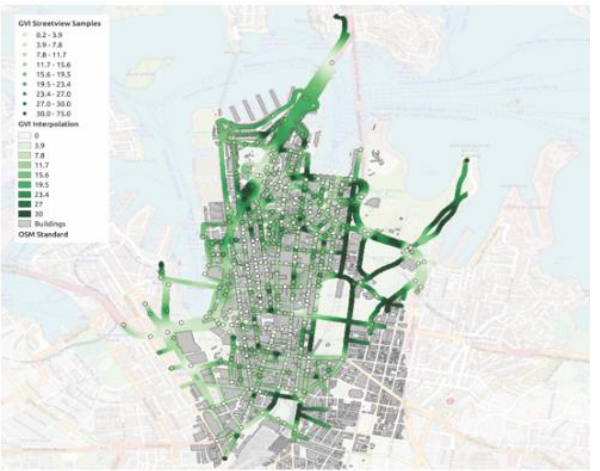

(d)

Figure 8. Urban greenery visualization for the Sydney CBD: (a) +45 degrees vertical angle; (b) 0 degrees vertical angle; (c) -45 degrees vertical angle; and (d) weighted average of all the three vertical angles. The legend represents the Green View Index (GVI) value ranges. 


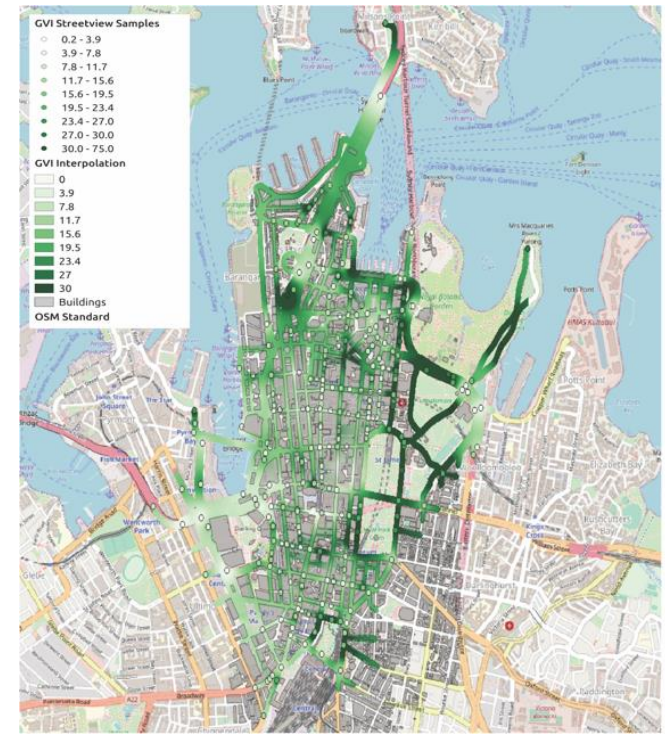

(a)

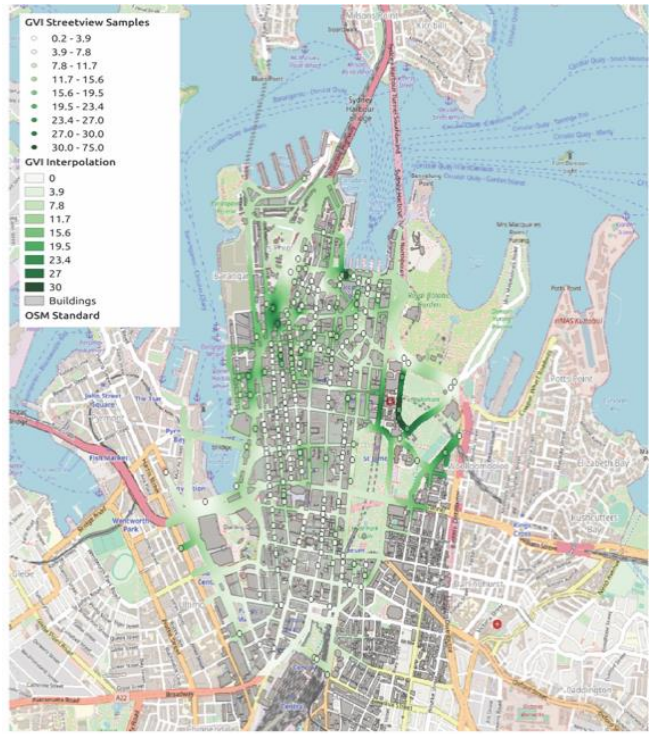

(b)

Figure 9. A comparison of urban greenery between (a) summer and (b) winter. The legend represents the GVI value ranges.

\subsection{Traffic Noise}

Here, we spatially visualize the simulated traffic noise by the NoiseModelling tool in OrbisGIS in Sydney. Using calibrated parameter set 2, we run three noise simulations for the morning peak, the off-peak period, and the afternoon peak. The results are illustrated in Figure 10a-c, respectively. In general, the areas near the Western Motorway (A4) and the Pacific Motorway (M1) turn out to be the noisiest areas in the Sydney CBD. In the inner CBD, the noisiest area lies at the intersection of Elizabeth Street and the King Street that are also the two noisiest streets in the city center. From the south, George Street is also noisy, but it becomes quieter after the intersection with Bathurst Street. The north part of the Sydney CBD including Circular Quay, Dawes Point, and The Rocks is quieter than the other parts. Overall, the spatial distribution of traffic noise exhibits high similarity between the morning and afternoon peaks, although the former is slightly noisier than the latter (see Figure 10d). The level of noise is the lowest, as expected, during the off-peak period.

\subsection{Spatio-Temporal Correlation between Urban Greenery and Traffic Noise}

The literature on urban environmental performance suggests the existence of a negative correlation between urban greenery and noise pollution. A study by Dzhambov et al. [35] showed neighborhoods with higher tree cover density seemed to lessen the negative effect of traffic noise. In another study, Margaritis and Kang [36] considered the correlations between green space-related morphology and noise pollution and observed that at the urban and kernel scales, cities with higher green space coverage were found to have lower day-evening-night noise levels. Mueller et al. [37] found reduced road traffic noise annoyance in urban areas is associated with residential tree cover density. In another study conducted in Gothenburg, Sweden, it was found that green areas were associated with reduced exposure to air pollution and leaves reduce noise levels at frequencies that are important for traffic noise [38].

Here, we conduct a spatio-temporal correlation analysis to better understand the relationship between urban greenery and traffic noise in Sydney (see Figure 11). While the analysis suggests a weak negative correlation, represented by the negative slope of the best fitted lines, we could not find strong evidence to make a conclusion on the impact of urban greenery on traffic noise mainly because of the limitations in the collected data. Nevertheless, we observed a relatively stronger correlation in winter, when the density 
of the urban green canopy is lower, compared to summer. Generally, locations with an estimated higher noise level have a lower measured greenery level.

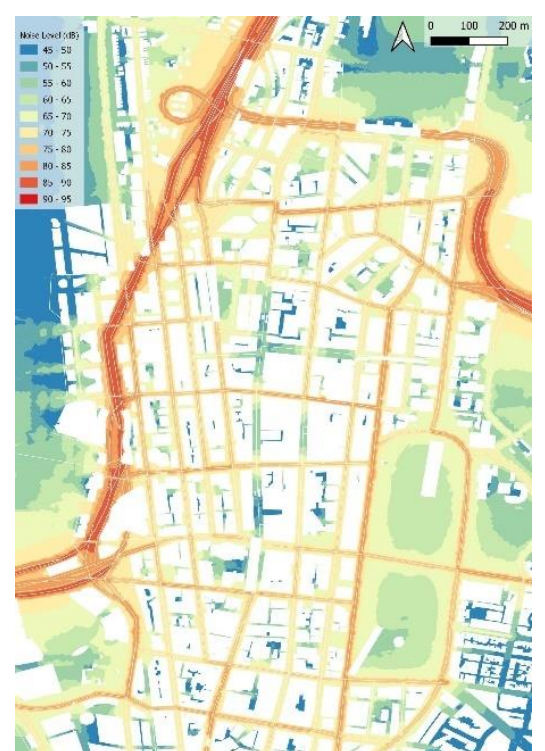

(a)

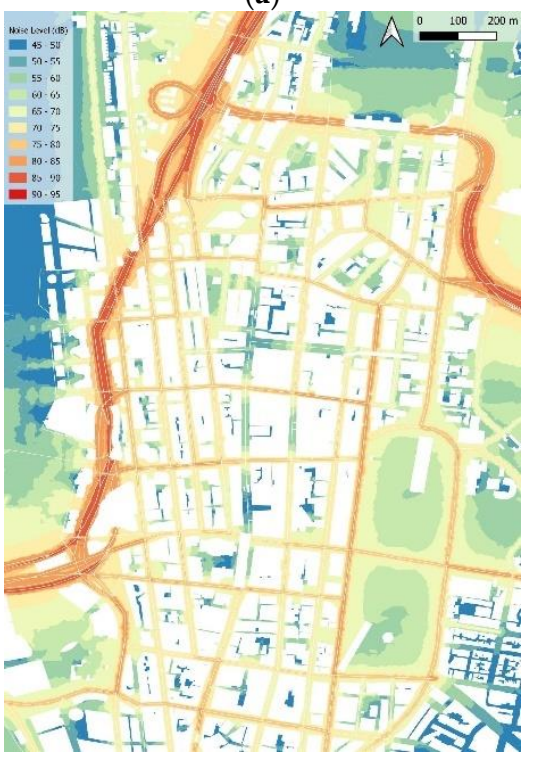

(c)

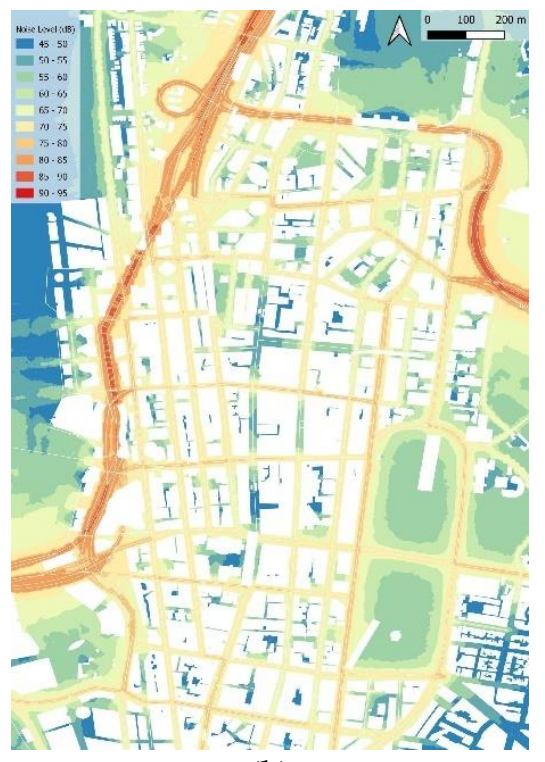

(b)

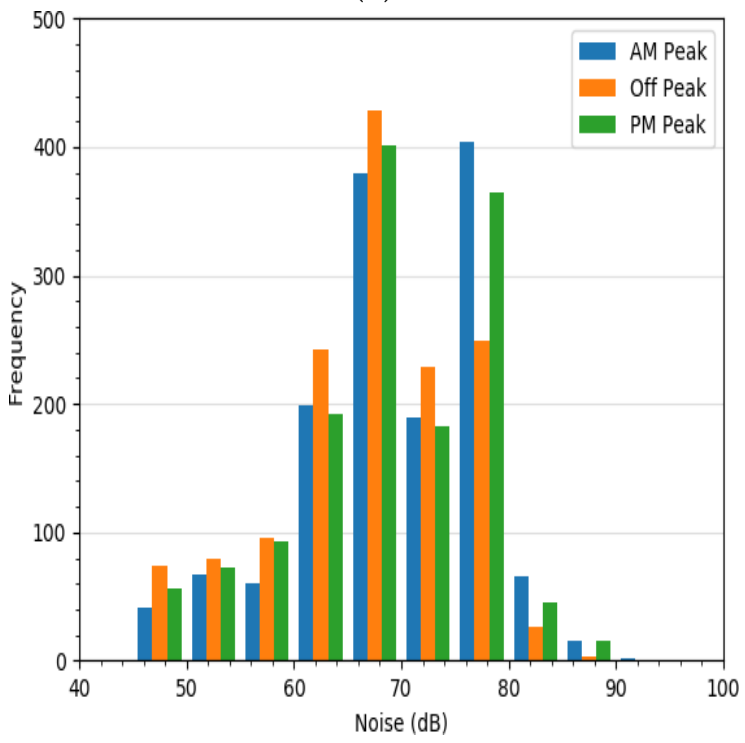

(d)

Figure 10. Spatial distribution of estimated traffic noise in the Sydney CBD for (a) the morning peak, (b) the off-peak period, and (c) the afternoon peak; and (d) distributions of the estimated noise levels for different times of day. 


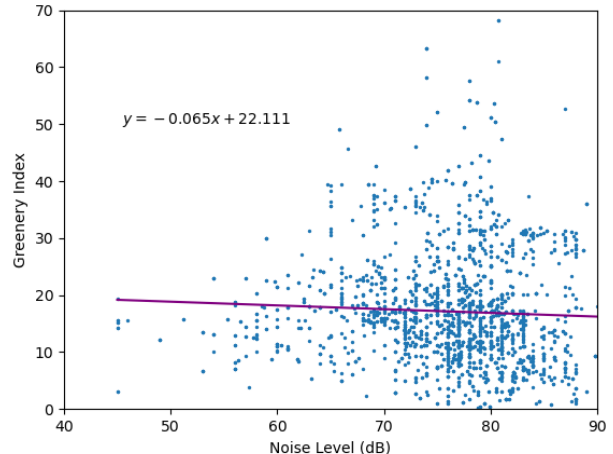

(a)

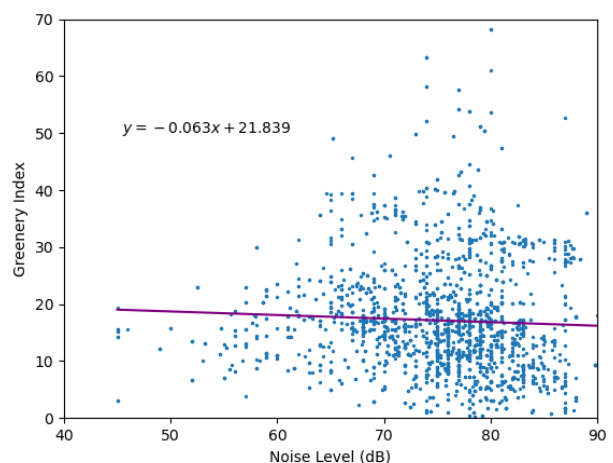

(c)

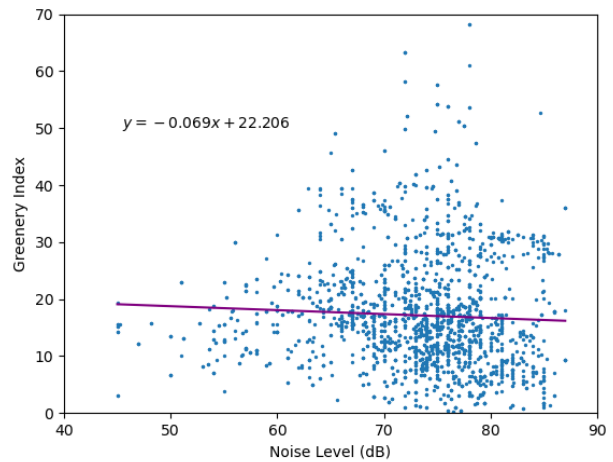

(e)

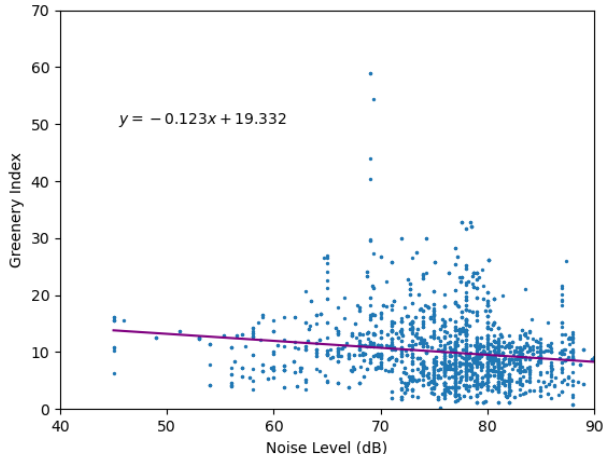

(b)

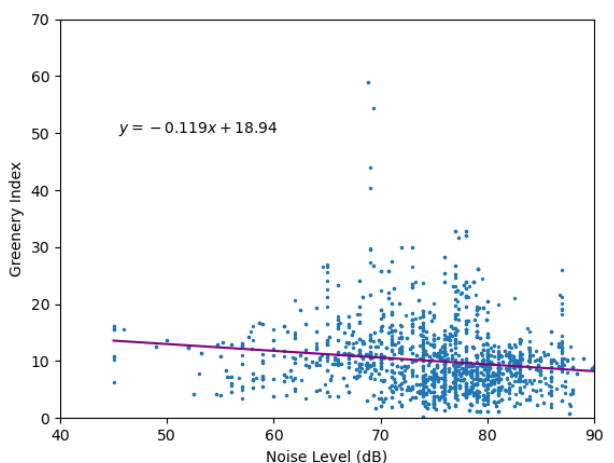

(d)

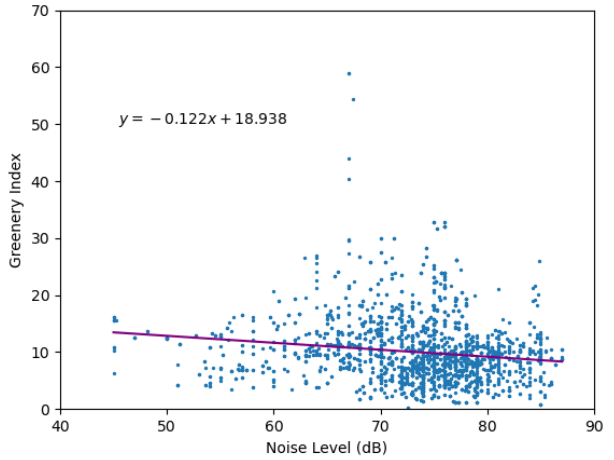

(f)

Figure 11. Correlation between estimated traffic noise levels and urban greenery index across the Sydney CBD in summer $(\mathbf{a}, \mathbf{c}, \mathbf{e})$ and winter $(\mathbf{b}, \mathbf{d}, \mathbf{f})$. Analysis is performed for the AM peak period $(\mathbf{a}, \mathbf{b})$, PM peak period $(\mathbf{c}, \mathbf{d})$, and off-peak period $(\mathbf{e}, \mathbf{f})$.

\section{Conclusions}

The growing availability of less traditional, distributed, crowd-sourced, unstructured, and mobile phone-based data has enabled a wide range of efficient and inexpensive measurements of urban environmental performance including air quality, temperature, noise, canopy, and human mobility. While emerging data sources are becoming more widely used to understand the performance and characteristics of the urban environment, there are still many challenges and unresolved issues with regard to their collection and processing as well as their use in modeling and prediction.

The paper demonstrates the applicability and advantages of emerging data sources in understanding and measuring the environmental performance of a city with a focus on urban greenery and traffic noise. Results show that street-level imagery data are a powerful emerging data source that can be used to quantify how well a city performs in its green canopy coverage and map its spatial and temporal distribution. Results also show 
that crowd-sourced mobile phone-based data enable estimation and visualization of how traffic noise emits and propagates throughout a city. The presented quantification and visualization frameworks and techniques in this paper are versatile and can accommodate other emerging data sources. For example, to acquire street view images, we could also resort to social media photos (e.g., Instagram). We also emphasize that there are always difficulties associated with collecting crowd-sourced data such as those from mobile phones. While privacy is certainly one concern from the public, how to effectively promote and/or incentivize the usage of certain applications and data sharing is another challenge to be addressed.

Author Contributions: Conceptualization, M.S. and Z.G.; methodology, all authors; data analysis, all authors; writing — original draft preparation, all authors; writing — review and editing, M.S. and Z.G.; visualization, T.L. and M.A.; supervision, M.S.; project administration, Z.G.; funding acquisition, M.S. and Z.G. All authors have read and agreed to the published version of the manuscript.

Funding: This research was funded by City of Sydney's Environmental Performance Innovation Grant 2019-2020.

Institutional Review Board Statement: Not applicable.

Informed Consent Statement: Not applicable.

Data Availability Statement: The data presented in this study are available on request from the corresponding author. The data are not publicly available due to contractual restrictions.

Acknowledgments: We thank T. Chen, L. Feng, Y. Wang, and X. Zheng for collection of empirical noise data and their contributions at the early stages of the project. We also acknowledge Veitch Lister Consulting (VLC) for providing us with traffic volume data across the Sydney network. We are thankful to the City of Sydney for supporting this research project.

Conflicts of Interest: The authors declare no conflict of interest.

\section{Appendix A}

Two imagery examples of urban greenery from different vertical angles.
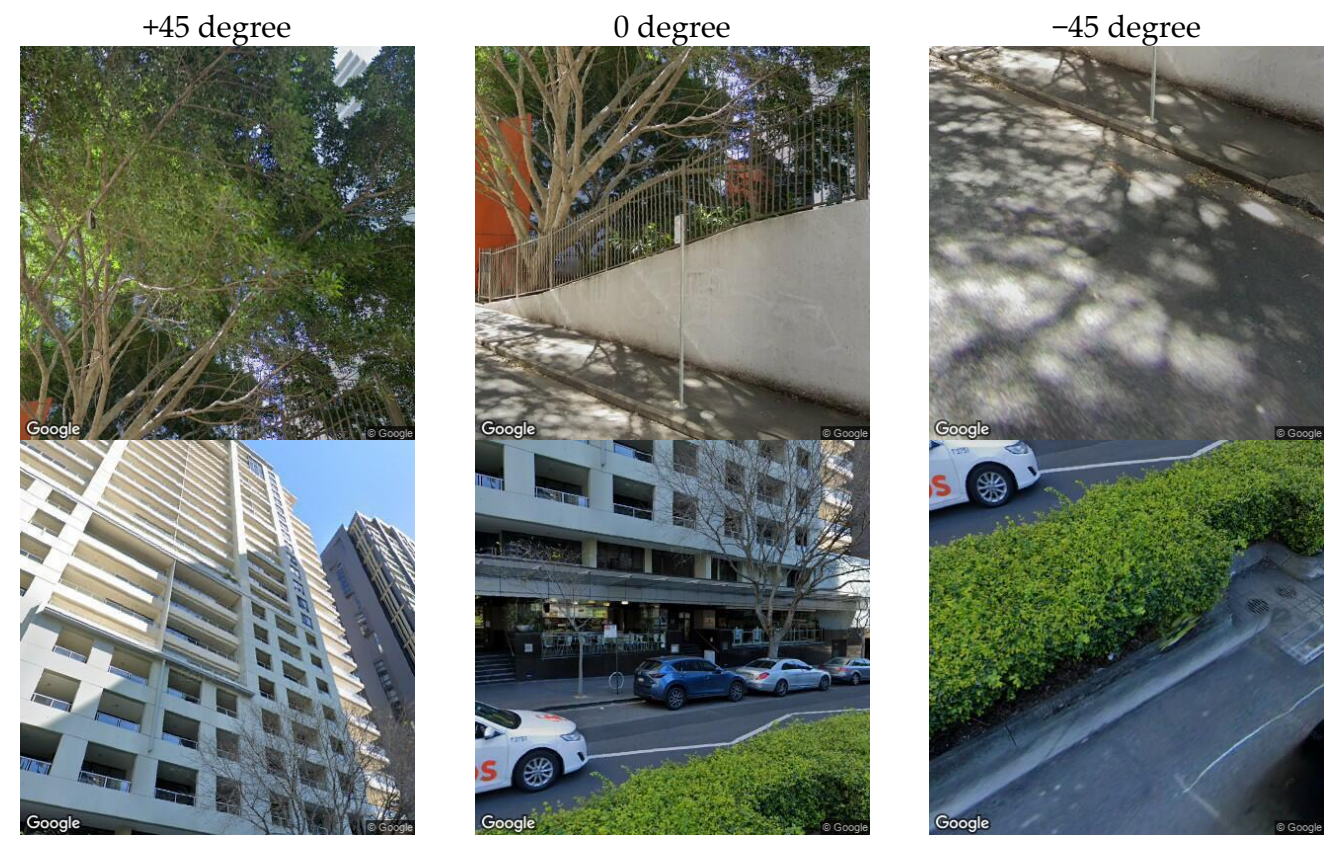

Figure A1. GSV images from three vertical angles for two locations.

\section{Appendix B}

An imagery example of temporal variation in urban greenery from Google Street View. 


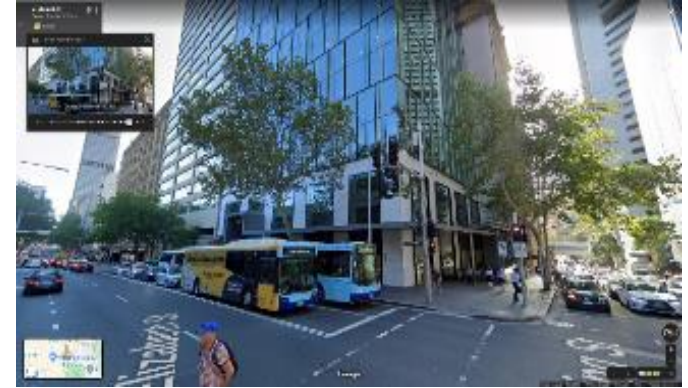

(a) February

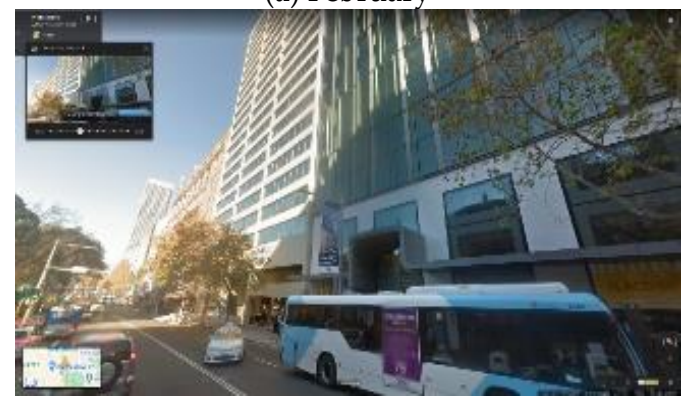

(c) May

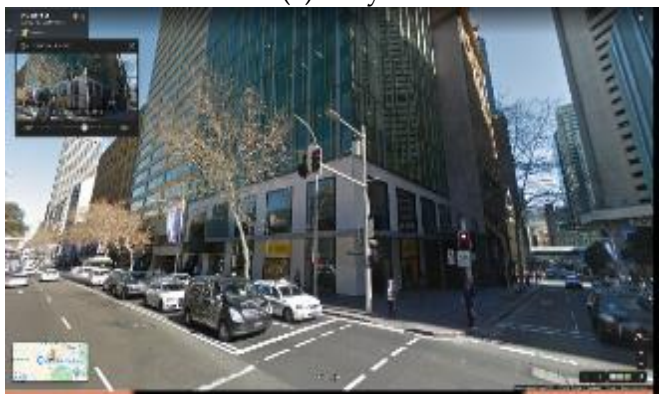

(e) August

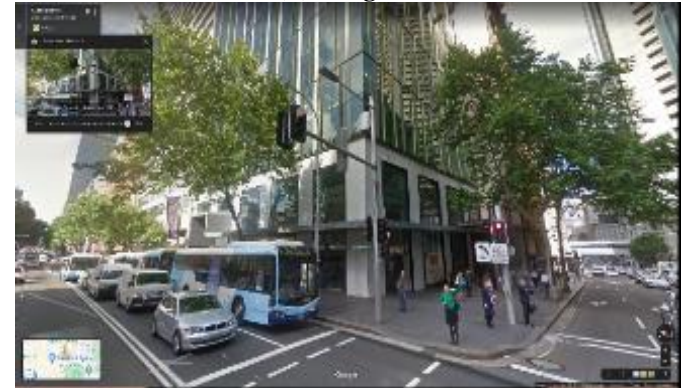

(g) November

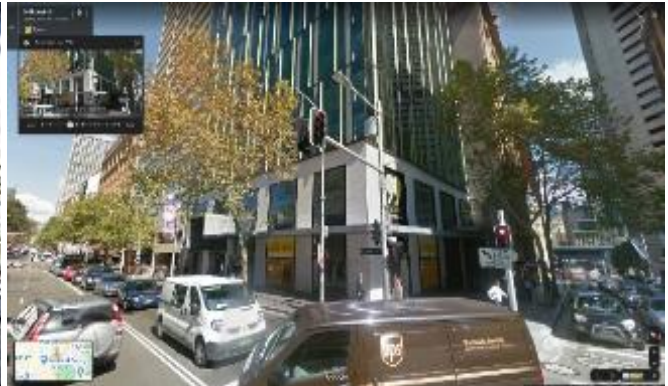

(b) April

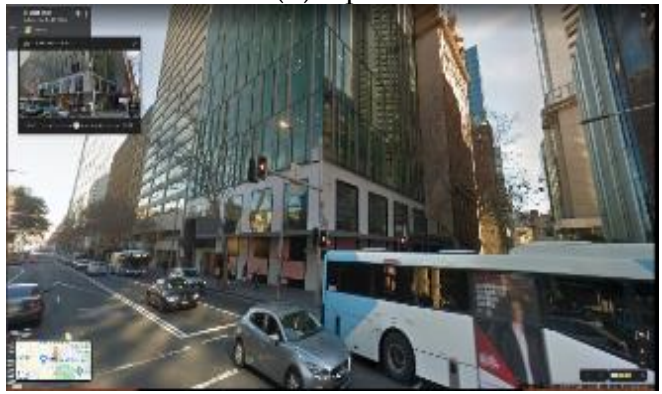

(d) July

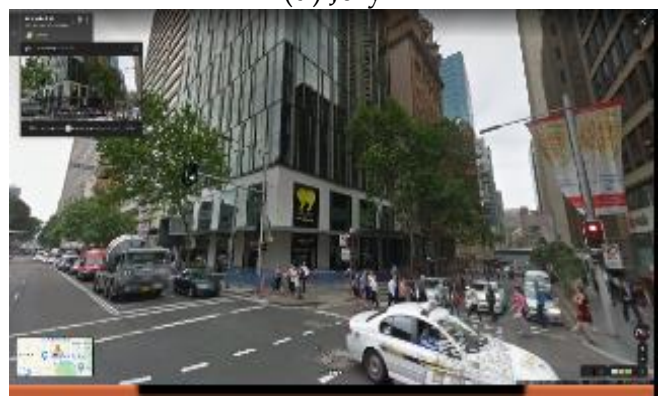

(f) October

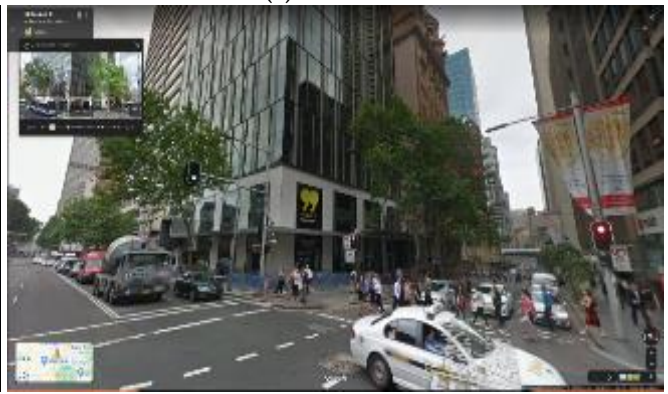

(h) December

Figure A2. GSV images at the same location but from different months.

\section{References}

1. Heaviside, C.; Macintyre, H.; Vardoulakis, S. The urban heat island: Implications for health in a changing environment. Curr. Environ. Health Rep. 2017, 4, 296-305. [CrossRef] [PubMed]

2. Rich, J.H.; Nielsen, O.A. Assessment of traffic noise impact. Int. J. Environ. Stud. 2004, 61, 19-29. [CrossRef]

3. Hammer, M.S.; Swinburn, T.K.; Neitzel, R.L. Environmental noise pollution in the United States: Developing an effective public health response. Environ. Health Perspect. 2014, 122, 115-119. [CrossRef] [PubMed]

4. Badach, J.; Dymnicka, M.; Baranowski, A. Urban vegetation in air quality management: A review and policy framework. Sustainability 2020, 12, 1258. [CrossRef]

5. Hwang, Y.H.; Nasution, I.K.; Amonkar, D.; Hahs, A. Urban green space distribution related to land values in fast-growing megacities, Mumbai and Jakarta-unexploited opportunities to increase access to greenery for the poor. Sustainability 2020, 12, 4982. [CrossRef]

6. $\quad$ Ling, T.-Y.; Hung, W.-K.; Lin, C.-T.; Lu, M.J.S. Dealing with green gentrification and vertical green-related urban well-being: A contextual-based design framework. Sustainability 2020, 12, 10020. [CrossRef] 
7. Jeon, J.Y.; Hong, J.Y.; Kim, S.M.; Kim, K.H. Noise indicators for size distributions of airborne particles and traffic activities in urban areas. Sustainability 2018, 10, 4599. [CrossRef]

8. Zhao, Z.; Wang, Y.B.; Hou, Y.L. Residents' spatial perceptions of urban gardens based on soundscape and landscape differences. Sustainability 2020, 12, 6809. [CrossRef]

9. Gozalo, G.R.; Suarez, E.; Montenegro, A.L.; Arenas, J.P.; Morillas, J.M.B.; Gonzalez, D.M. Noise estimation using road and urban features. Sustainability 2020, 12, 9217. [CrossRef]

10. World Health Organization. Environmental Noise Guidelines for the European Region; WHO Regional Office for Europe: Copenhagen, Denmark, 2018.

11. Berglund, B.; Lindvall, T.; Schwela, D.H. (Eds.) Guidelines for Community Noise; World Health Organization: Geneva, Switzerland, 1999.

12. Wolch, J.R.; Byrne, J.; Newell, J.P. Urban green space, public health, and environmental justice: The challenge of making cities "just green enough". Landsc. Urban Plan. 2014, 125, 234-244. [CrossRef]

13. Comission Directive. Directive 2002/44/EC of the European Parliament and the Council of 25 June 2002 on the minimum health and safety requirements regarding the exposure of workers to the risks arising from physical agents (vibration)(sixteenth individual Directive within the meaning of Article 16 (1) of Directive 89/391/EEC). Off. J. Eur. Union 2002, 117, 6-7.

14. Picaut, J.; Fortin, N.; Bocher, E.; Petit, G.; Aumond, P.; Guillaume, G. An open-science crowdsourcing approach for producing community noise maps using smartphones. Build. Environ. 2019, 148, 20-33. [CrossRef]

15. Zuo, F.; Li, Y.; Johnson, S.; Johnson, J.; Varughese, S.; Copes, R.; Liu, F.; Wu, H.J.; Hou, R.; Chen, H. Temporal and spatial variability of traffic-related noise in the City of Toronto, Canada. Sci. Total Environ. 2014, 472, 1100-1107. [CrossRef] [PubMed]

16. Suarez, E.; Barros, J.L. Traffic noise mapping of the city of Santiago de Chile. Sci. Total Environ. 2014, 466, 539-546. [CrossRef] [PubMed]

17. Cai, M.; Zou, J.F.; Xie, J.M.; Ma, X.L. Road traffic noise mapping in Guangzhou using GIS and GPS. Appl. Acoust. 2015, 87, 94-102. [CrossRef]

18. Bilasco, S.; Govor, C.; Rosca, S.; Vescan, I.; Filip, S.; Fodorean, I. GIS model for identifying urban areas vulnerable to noise pollution: Case study. Front. Earth Sci. 2017, 11, 214-228. [CrossRef]

19. Faryadi, S.; Taheri, S. Interconnections of urban green spaces and environmental quality of Tehran. Int. J. Environ. Res. 2009, 3, 199-208.

20. Jiang, B.; Chang, C.Y.; Sullivan, W.C. A dose of nature: Tree cover, stress reduction, and gender differences. Landsc. Urban Plan. 2014, 132, 26-36. [CrossRef]

21. Kuo, F.E.; Sullivan, W.C. Aggression and violence in the inner city-Effects of environment via mental fatigue. Environ. Behav. 2001, 33, 543-571. [CrossRef]

22. Ye, Y.; Richards, D.; Lu, Y.; Song, X.P.; Zhuang, Y.; Zeng, W.; Zhong, T. Measuring daily accessed street greenery: A human-scale approach for informing better urban planning practices. Landsc. Urban Plan. 2019, 191, 13. [CrossRef]

23. Kumakoshi, Y.; Chan, S.Y.; Koizumi, H.; Li, X.J.; Yoshimura, Y. Standardized green view index and quantification of different metrics of urban green vegetation. Sustainability 2020, 12, 7434. [CrossRef]

24. Yang, Y.Y.; He, D.S.; Gou, Z.H.; Wang, R.Y.; Liu, Y.; Lu, Y. Association between street greenery and walking behavior in older adults in Hong Kong. Sustain. Cities Soc. 2019, 51, 101747. [CrossRef]

25. Li, X.J.; Zhang, C.R.; Li, W.D.; Kuzovkina, Y.A. Environmental inequities in terms of different types of urban greenery in Hartford, Connecticut. Urban For. Urban Green. 2016, 18, 163-172. [CrossRef]

26. Klingberg, J.; Konarska, J.; Lindberg, F.; Johansson, L.; Thorsson, S. Mapping leaf area of urban greenery using aerial LiDAR and ground-based measurements in Gothenburg, Sweden. Urban For. Urban Green. 2017, 26, 31-40. [CrossRef]

27. Treepedia. Exploring the Green Canopy in Cities around the World. Available online: http://senseable.mit.edu/treepedia (accessed on 10 July 2019).

28. Li, X.J.; Zhang, C.R.; Li, W.D.; Ricard, R.; Meng, Q.Y.; Zhang, W.X. Assessing street-level urban greenery using Google Street View and a modified green view index. Urban For. Urban Green. 2015, 14, 675-685. [CrossRef]

29. Bocher, E.; Guillaume, G.; Picaut, J.; Petit, G.; Fortin, N. NoiseModelling: An open source GIS based tool to produce environmental noise maps. ISPRS Int. J. Geo Inf. 2019, 8, 130. [CrossRef]

30. Szopinska, K. Creation of theoretical road traffic noise model with the help of GIS. In Proceedings of the Environmental Engineering 10th International Conference, Vilnius, Lithuania, 27-28 April 2017.

31. Kephalopoulos, S.; Paviotti, M.; Anfosso Ledee, F.; Jones, N. Advances in the development of common noise assessment methods in Europe: The CNOSSOS-EU framework for strategic environmental noise mapping. Sci. Total Environ. 2014, 482, 400-410. [CrossRef]

32. Commission Directive. Commission Directive (EU) 2015/996 of 19 May 2015 establishing common noise assessment methods according to directive 2002/49/EC of the European Parliament and of the Council. Off. J. Eur. Union 2015, $168,58$.

33. Planwisely. Latest Zenith Traffic Volume Data Released. Available online: https://planwisely.io/blog/2019/03/12/LatestZenith-Traffic-Volume-Data-Released.html (accessed on 10 July 2019).

34. Bureau of Meteorology. Government of Australia. Available online: http://www.bom.gov.au/climate/austmaps/about-ndvimaps.shtml (accessed on 10 July 2019). 
35. Dzhambov, A.M.; Markevych, I.; Tilov, B.G.; Dimitrova, D.D. Residential greenspace might modify the effect of road traffic noise exposure on general mental health in students. Urban For. Urban Green. 2018, 34, 233-239. [CrossRef]

36. Margaritis, E.; Kang, J. Relationship between green space-related morphology and noise pollution. Ecol. Indic. 2017, 72, 921-933. [CrossRef]

37. Mueller, W.; Steinle, S.; Parkka, J.; Parmes, E.; Liedes, H.; Kuijpers, E.; Pronk, A.; Sarigiannis, D.; Karakitsios, S.; Chapizanis, D.; et al. Urban greenspace and the indoor environment: Pathways to health via indoor particulate matter, noise, and road noise annoyance. Environ. Res. 2020, 180, 13. [CrossRef] [PubMed]

38. Klingberg, J.; Broberg, M.; Strandberg, B.; Thorsson, P.; Pleijel, H. Influence of urban vegetation on air pollution and noise exposure-A case study in Gothenburg, Sweden. Sci. Total Environ. 2017, 599, 1728-1739. [CrossRef] [PubMed] 